\title{
Labetalol Hypotensive Anesthetic Protocol Paves the Way to Safe Open Abdominal Myomectomy
}

\author{
Ahmed E Salem ${ }^{1 *}$, Ahmed M Hagras ${ }^{2}$ and Hesham M Abo-Ragab ${ }^{3}$ \\ ${ }^{1}$ Department of Anaesthesia \& ICU, Tanta University, Egypt \\ ${ }^{2}$ Department of Obstetrics \& Gynecology, Tanta University, Egypt \\ ${ }^{3}$ Department of Obstetrics \& Gynecology, Benha University, Egypt
}

Submission: March 07, 2017; Published: June 08, 2017

*Corresponding author: Ahmed E Salem, Department of Anesthesia \& ICU, Faculty of Medicine, Tanta University, Egypt, Tel: 01001802978;

Email: essamahmed20016@gmail.com

\begin{abstract}
Objectives: Evaluating effect of oral labetalol pre-medication followed by low-dose intraoperative (IO) labetalol infusion on IO heart rate (HR) and mean arterial pressure (MAP), blood loss and need for transfusion and urine output (UOP) of patients undergoing open abdominal myomectomy.

Patient \& methods: Eighty-eight patients were randomly divided into: Study patients received $200 \mathrm{mg}$ oral labetalol 2-hr before surgery and IO labetalol infusion $(0.2 \mathrm{mg} / \mathrm{kg} / \mathrm{hr})$ till completion of myomectomy. Control patients received placebo infusion and all patients received the same anesthetic protocol.

Results: Operative blood loss and transfusion needs were significantly lower, but UOP was significantly higher in study than control patients. Oral labetalol significantly decreased preoperative HR and MAP of study patients compared to their baseline measures and to control patients. Oral labetalol significantly decreased HR and MAP elevations after induction and intubation compared to control patients. Labetolol infusion significantly decreased HR and MAP till stoppage of infusion compared to other measures and to control patients. Labetalol infusion allowed stability of HR and MAP with non-significant difference between measures till stoppage of infusion. Extubation significantly elevated HR and MAP in control patients, but non-significantly in study patients. Postoperative (PO), HR and MAP were significantly lower in study patients compared to baseline measures and to PO measures in control patients. PO hemoglobin concentration was significantly lower in all patients than preoperative concentrations, but concentration deficit was significantly lower in study than control patients.
\end{abstract}

Conclusion: The applied protocol of labetalol hypotensive anesthesia improved anesthetic and surgical outcome of myomectomy.

Keywords: Labetalol; Hypotensive anesthesia; Myomectomy

Abbreviations: IO: Intraoperative; PO: Postoperative; MAP: Mean Arterial Pressure; OAM: Open Abdominal Myomectomy; SNP: Sodium Nitroprusside

\section{Introduction}

Myomectomy is the gold standard uterine-sparing surgery for symptomatizing uterine fibroid [1], but intraoperative (IO) bleeding is still a challenge [2]. Hypotensive anesthesia allowed significant decrease of blood loss without compromising vital organ perfusion [3] and subsequently reduces transfusion requirements and minimizes allogenic transfusions risks [4]. Labetalol is a combined $\beta$ - and $\alpha 1$ adrenoceptors antagonist [5]. Oral labetalol is readily absorbed in man [6]. Peak plasma level was achieved after 2.5-minute and 20-120 minutes after intravenous and oral administration, respectively [7], peak effect within 1-4hr after oral intake [8] and elimination half-life of 5 to 8 hours [6].

\section{Hypothesis}

Pre-anesthetic medication with oral labetalol followed by lowdose IO labetalol infusion can improve anesthetic and surgical outcome of open abdominal myomectomy (OAM).

Objectives: Evaluation of effect of the proposed hypotensive protocol on IO heart rate (HR) and mean arterial pressure (MAP), blood loss and need for transfusion and tissue perfusion judged by urine output (UOP) of patients undergoing OAM.

Design: Prospective comparative study. 
Setting: University and Insurance hospitals, Tanta and Benha, Egypt.

\section{Patient \& Methods}

This study was conducted since Oct 2014 till Nov 2016. Study protocol was approved by the Local Ethical Committee. Women assigned for myomectomy and signed written fully informed consent were included in the study. Exclusion criteria included presence of multiple myomas necessitating hysterectomy, gynecological malignancy, cardiac diseases or history of coagulopathy. Clinical evaluations entail collection of demographic data, complete gynecological and ultrasonographic examinations and routine laboratory investigations. Women with hemoglobin concentration of $\leq 7 \mathrm{gm} / \mathrm{dl}$ received preoperative blood transfusion to adjusted $\mathrm{Hb}$. Conc. of $\geq 8 \mathrm{gm} / \mathrm{dl}$.

Patients fulfilling the inclusion criteria were randomly, using sealed envelops prepared by blinded anesthetic assistant, allocated into two equal study groups according to the applied anesthetic procedure; Study patients followed the hypotensive protocol and control patients received normotensive anesthesia.

\section{Preparation of labetalol infusion}

Labetalol infusion was prepared by mixing $4 \mathrm{ml}$ labetalol (Trandate injection, Aspen Pharmacare, South Africa, $5 \mathrm{mg} / \mathrm{ml}$ ) in $500 \mathrm{cc}$ physiological saline to provide a concentration of $0.04 \mathrm{mg} /$ $\mathrm{ml}$ saline. Infusion rate was adjusted at $6 \mathrm{ml} / \mathrm{min}$, to provide the patient by $0.24 \mathrm{mg} / \mathrm{min}$, i.e., $14.4 \mathrm{mg} / \mathrm{hr}$ and if the patient weighs $70 \mathrm{~kg}$ body weight so the dose received will be $0.206 \mathrm{mg} / \mathrm{kg} / \mathrm{hr}$ [9]. Labetalol infusion rate was adjusted to provide a target MAP of 55$60 \mathrm{mmHg}[10]$ but not exceeding the recommended safe maximal dose of $300 \mathrm{mg}$ on occasion of infusion [11]. Plain saline infusion was prepared as placebo for control patients. An assistant, not included in the study, was responsible for infusion preparations and distribution between patients and adjustment of rates.

\section{Hypotensive protocol}

Baseline HR and MAP were non-invasively determined, then study patients received $200 \mathrm{mg}$ oral labetalol (Trandate, Aspen Pharmacare, South Africa, 100mg tablets), while control patients received a placebo tablet two hours prior to surgery. HR and MAP were determined preoperatively, after induction of anesthesia and after tracheal intubation. Then, labetalol and placebo infusions were started till myomectomy was completed and then were stopped to allow restoration of blood pressure to achieve perfect hemostasis.

\section{Anesthetic Procedure}

Patients of control group were premedicated by midazolam $0.02 \mathrm{mg} / \mathrm{kg}$. Anesthesia was induced, in groups, using propofol $2 \mathrm{mg} / \mathrm{kg}$, fentanyl $1-2 \mathrm{ug} / \mathrm{kg}$, and rocuronium $0.6 \mathrm{mg} / \mathrm{kg}$, and was continued with sevoflurane, fentanyl and rocuronium. After tracheal intubation, the lungs were ventilated with $100 \% \mathrm{O}_{2}$ in air using a semi-closed circle system for a tidal volume of 6-8 ml/ $\mathrm{kg}$, and end-tidal carbon dioxide $\left(\mathrm{paCO}_{2}\right)$ of $32-35 \mathrm{mmHg}$. Patients were continuously non-invasively monitored for MAP and HR.

\section{Study outcome}

\section{Primary outcome included}

A. Effect of oral labetalol pre-medication on HR and MAP determined after induction and tracheal intubation.

B. Effect of labetalol infusion on intraoperative HR and MAP estimated every 10 minutes till end of surgery and at time of infusion stoppage.

\section{Secondary outcome included}

a. IO blood loss, frequency of blood transfusion

b. Amount of intraoperative UOP.

c. Hemoglobin concentration (Hb. Conc.) estimated immediately after surgery and concentration deficit in relation to preoperative concentration.

\section{Statistical Analysis}

Sample size was calculated using the standard nomogram proposed by Kraemer \& Thiemann [12] and a sample size of $\geq 40$ patients per group was determined to be sufficient to detect a difference at the $5 \%$ significance level and give the trial $80 \%$ power. Results were analyzed using paired t test, one-way ANOVA with post-hoc Tukey HSD Test and Chi-square test $\left(\mathrm{X}^{2}\right.$ test). Statistical analysis was conducted using the SPSS (Version $15,2006)$ for Windows statistical package. $\mathrm{P}$ value $<0.05$ was considered significant.

Results

Table 1: Preoperative and operative data of patients of studied groups.

\begin{tabular}{|c|c|c|c|c|}
\hline Time & Data & $\begin{array}{c}\text { Control } \\
\text { Group }\end{array}$ & $\begin{array}{c}\text { Study } \\
\text { Group }\end{array}$ & P Value \\
\hline Preoperative & Age (years) & $36.4 \pm 7.3$ & $37.6 \pm 8$ & NS \\
\hline & $\begin{array}{c}\text { Body mass } \\
\text { index (kg/ } \\
\left.\mathrm{m}^{2}\right)\end{array}$ & $29.7 \pm 2.2$ & $29.5 \pm 2.4$ & NS \\
\hline $\begin{array}{c}\text { Need for } \\
\text { blood } \\
\text { transfusion }\end{array}$ & $11(23.9 \%)$ & $15(32.6 \%)$ & NS \\
\hline Intraoperative & $\begin{array}{c}\text { Enrolled } \\
\text { Operative } \\
\text { time (min) }\end{array}$ & $43(93.5 \%)$ & $45(97.8 \%)$ & NS \\
\hline $\begin{array}{c}\text { Operative } \\
\text { blood loss } \\
\text { (ml) }\end{array}$ & $874.3 \pm 307$ & $709.6 \pm 315$ & 0.022 \\
\hline $\begin{array}{c}\text { Need for } \\
\text { blood } \\
\text { transfusion }\end{array}$ & $9(26.5 \%)$ & $3(6.7 \%)$ & 0.013 \\
\hline $\begin{array}{c}\text { Urine } \\
\text { output (ml/ } \\
\text { kg/hr) }\end{array}$ & $2.04 \pm 0.8$ & $1.74 \pm 0.5$ & 0.038 \\
\hline
\end{tabular}

Data are presented as mean $\pm S D$, numbers, percentages; $P$ value indicates difference between both groups; NS: Non-significant, $p<0.05$ : significant difference.

The study included 92 patients, 26 patients (28.3\%) required preoperative blood transfusion for correction of anemia and 4 patients were excluded during surgery. Mean operative blood 


\section{Journal of Anesthesia \& Intensive Care Medicine}

loss and need for transfusion were significantly lower, but intraoperative UOP was significantly higher in patients of study group. Pre- and intraoperative data are shown in Table 1. Oral labetalol significantly decreased preoperative HR and MAP of patients of study group compared to their baseline measures and to preoperative measures of control patients. Induction of anesthesia and tracheal intubation significantly increased HR and MAP compared to baseline and preoperative measures in both groups. However, oral labetalol significantly decreased these elevations compared estimates of control patients.

IO labetolol infusion significantly decreased HR and MAP till stoppage of infusion in comparison to other measures and to measures of patients of control group. Moreover, labetalol infusion allowed stability of HR and MAP with non-significant difference between measures at $10^{-}, 20^{-}, 30^{-}, 40^{\circ}$ min after start of infusion and at time of stoppage of infusion. Extubation significantly elevated HR and MAP in comparison to other IO measurements in control group, while the difference was non-significant in patients of study group. At $1 \mathrm{hr}$ and $2 \mathrm{hr}$ postoperative (PO), mean HR and MAP levels showed non-significant difference versus baseline and preoperative measures in control group, while were significantly lower compared to baseline measures in patients of study group and to PO measures in patients of control group (Table 2). Postoperative $\mathrm{Hb}$. Conc. was significantly lower in patients of both groups compared to preoperative concentration, but was non-significantly lower in patients of control group than study group. On contrary, concentration deficit was significantly lower in patients of study group compared to control group (Table 3).

Table 2: Mean $( \pm S D)$ Heart rate and mean arterial pressure estimated in patients of studied groups.

\begin{tabular}{|c|c|c|c|c|c|}
\hline Parameter & Heart Rate (Beat/Min) & $\begin{array}{c}\text { Mean Arterial } \\
\text { Pressure (Mmhg) }\end{array}$ & & & \\
\hline Time Group & Control & Study & Control & Study & \\
\hline Baseline & $84.6 \pm 5.9$ & $86.4 \pm 7.9^{*}$ & $90 \pm 3$ & $91.1 \pm 2.3$ & \\
\hline $\begin{array}{l}\text { Preoperative(2-hr } \\
\text { after baseline) }\end{array}$ & $85.3 \pm 6.2$ & $78.8 \pm 8^{*} \dagger$ & $87.3 \pm 4.5$ & $81.7 \pm 3.5^{*}+$ & \\
\hline After induction & $89.5 \pm 7.1 † \ddagger$ & $82.1 \pm 8.3^{*}$ & $93.7 \pm 3.6 † \ddagger$ & $83.9 \pm 2.6^{*} \dagger$ & \\
\hline $\begin{array}{l}\text { After tracheal } \\
\text { intubation }\end{array}$ & $92.1 \pm 5.6 \dagger \neq$ & $83.8 \pm 7.7^{*}$ & $97.4 \pm 4.5 \dagger \neq \mathbb{T}$ & $84.2 \pm 2.5 * \dagger$ & \\
\hline \multirow[t]{4}{*}{ After start of infusion } & 10-min & $80.2 \pm 8 \dagger \neq \uparrow \# \$$ & $64.1 \pm 9.1^{*}+キ \llbracket \# \$$ & 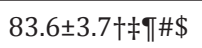 & $68.8 \pm 6^{*} \dagger \neq \Upsilon \#$ \\
\hline & 20-min & $75.7 \pm 4.9 \dagger キ \llbracket \# \$$ & $63.9 \pm 9.6^{*} † キ \llbracket \# \$$ & $84.5 \pm 2.6 † \ddagger \rrbracket \# \$$ & $65.8 \pm 5 * 十 キ \llbracket \#$ \\
\hline & 30-min & $76 \pm 6.3 † \ddagger \uparrow \# \$$ & $66.1 \pm 12 * \dagger \neq \rrbracket \# \$$ & $81.8 \pm 5.2 \dagger \neq \rrbracket \# \$$ & $67.7 \pm 6 * \dagger ‡ \uparrow \#$ \\
\hline & 40-min & $77.2 \pm 5.1 \dagger \neq \llbracket \# \$$ & $64.3 \pm 9 * \dagger \neq \uparrow \# \$$ & $79.5 \pm 7 \dagger \neq \Upsilon \# \$$ & $65.5 \pm 6.7 * \dagger \neq \llbracket \#$ \\
\hline $\begin{array}{l}\text { At time of end of } \\
\text { infusion }\end{array}$ & $78.3 \pm 6.3 † \ddagger \rrbracket \# \$$ & $64.5 \pm 13.9 * \dagger \neq \pi \# \$$ & $82.4 \pm 5.3 † \ddagger \rrbracket \# \$$ & $65.1 \pm 6.5^{*}+\ddagger \rrbracket \#$ & \\
\hline After extubation & $88.6 \pm 7.1 \#$ & $77.2 \pm 6.8^{*}+\Phi \#$ & $94.3 \pm 3.3 † \ddagger$ & $68.8 \pm 5^{*} † \neq \rrbracket \#$ & \\
\hline \multirow[t]{2}{*}{ PO } & 1-hr & $80.5 \pm 5.7$ & $73.5 \pm 8.6^{*} \dagger$ & $89.9 \pm 2.6$ & $72.9 \pm 2.5 * \dagger \neq$ \\
\hline & 2-hr & $82.5 \pm 6.6$ & $76 \pm 6.5^{*} \dagger$ & $89 \pm 4.1$ & $79 \pm 5.7^{*} \dagger$ \\
\hline
\end{tabular}

*: Significant difference versus control group; $\uparrow$ : Significant difference versus baseline measures; $\ddagger$ : significant difference versus preoperative measures; ๆ: Significant difference versus after induction estimates; \#: Significant difference versus after tracheal intubation estimates; \$: Significant difference versus after extubation estimates.

Table 3: Mean $( \pm \mathrm{SD})$ preoperative and PO hemoglobin concentration with PO deficit in patients of studied groups.

\begin{tabular}{|c|c|c|c|}
\hline Parameter Group & Control & Study & P value \\
\hline Preoperative $(\mathrm{gm} \%)$ & $9.07 \pm 0.88$ & $8.77 \pm 0.69$ & NS \\
\hline PO (gm\%) & $8.33 \pm 0.83$ & $8.38 \pm 0.61$ & NS \\
\hline P1 value & 0.001 & 0.005 & \\
\hline Concentration deficit & $0.73 \pm 0.41$ & $0.39 \pm 0.18$ & 0.001 \\
\hline
\end{tabular}

$P$ value indicates difference between both groups; $P 1$ value indicates difference between preoperative and PO measures; NS: Nonsignificant, $p<0.05$ : significant difference.

\section{Discussion}

Oral labetalol pre-medication significantly lowered preoperative HR and MAP in study patients and allowed blunting of the pressor reflexes associated with induction of anesthesia and tracheal intubation than in control patients. These findings spot light on the possibility for using oral labetalol as a preanesthetic medication and go in hand with Ryu et al. [13] who found labetalol injection either before or after laryngoscopy and tracheal intubation was associated with lower incidence of tachycardia and less increase in rate-pressure product. Also, Meftahuzzaman et al. [14] detected significantly minimal increase in HR and MAP in patients received bolus dose of labetalol or fentanyl prior to tracheal intubation compared to control patients with significant difference in favor of labetalol and concluded that labetalol is better agent for attenuation of laryngoscopic and intubation reflex than fentanyl.

Recently, El-Shmaa \& El-Baradey [15] reported significant decrease in HR and MAP with labetalol and dexmedetomidine than with saline in response to laryngoscopy and intubation and Sharma et al. [16] found both labetalol and nifedipine were effective for control of persistent postpartum hypertension, 
but labetalol achieved control significantly more often with the starting dose and had fewer side effects. In support of the use of oral $\beta$-blockers for preoperative preparation whenever deliberate hypotension is required, Apipan \& Rummasak [17], Amr \& Amin $[18,19]$ and Kim et al. [20] reported that premedication with oral propranolol, oral atenolol or oral enalapril before hypotensive anesthesia effectively reduced heart rate, amount of blood loss, and blood transfused with better quality of surgical field.

Labetalol infusion allowed proper hemodynamic control throughout operative time manifested as significantly lower MAP with subsequent significant reduction of operative field bleeding, transfusion requirement and significantly lower hemoglobin deficit compared control patients. These results coincided with previous work documented that hypotensive anesthesia reduced IO blood loss and improved the quality of the surgical field [2123]. In line with the use of labetalol infusion for maintenance of low IO blood pressure, Hadavi et al. [24] detected a little difference between labetalol and nitroglycerine on IO blood loss and surgical field quality in rhinoplasty surgery and Jeong et al. [25] found sevoflurane plus a "supportive" agent either; esmolol, labetalol, metoprolol, nicardipine, and dexmedetomidine may offer significant advantage of reducing patients' MAP than sevoflurane alone during orthognathic surgery.

The reported non-significant differences between IO measurements of MAP throughout operative time assured the proper control of labetalol infusion on blood pressure during surgical manipulation. In support of this finding, Chung et al. [26] demonstrated that labetalol pretreatment $(1.2 \mathrm{mg} / \mathrm{kg})$ with supplemental intravenous sodium nitroprusside (SNP) provides more favorable blood pressure control during surgical resection of pheochromocytoma than with SNP alone.

Moreover, immediate and 2-hr PO MAP measures in study patients were significantly lower compared to baseline measures and to PO pressure in control patients. These data indicated that labetalol allowed proper emergence from anesthesia that was maintained postoperatively. These findings go in hand with Ryu et al. [13] who found time to return to normotension after the loading dose was longer with labetalol than nicardipine \& Mashour et al. [27] also found the use of IO esmolol or labetalol is not associated with stroke after non-cardiac surgery, while metoprolol was associated with a 3.3-fold increase in perioperative stroke. Moreover, Sanath Kumar et al. [28] presented four cases of phaeochromocytoma prepared with oral labetalol and reported rare intraoperative surges in blood pressure during tumor manipulation and all patients had an uneventful PO recovery. Sirivanasandha et al. [29] documented that labetalol is a good alternative drug to control hypertensive response during emergence from anesthesia for post-craniotomy.

\section{Conclusion}

The applied protocol of oral labetalol pre-medication and lowdose IO labetalol infusion as a modality for hypotensive anesthesia improved anesthetic and surgical outcome of myomectomy.

\section{References}

1. Flyckt R, Coyne K, Falcone T (2017) Minimally Invasive Myomectomy. Clin Obstet Gynecol 60(2): 252-272.

2. Kongnyuy EJ, Wiysonge CS (2014) Interventions to reduce haemorrhage during myomectomy for fibroids. Cochrane Database Syst Rev 9(11): CD005355.

3. Choi WS, Samman N (2008) Risks and benefits of deliberate hypotension in anesthesia: a systematic review. Int J Oral Maxillofac Surg 37(8): 687-703.

4. Ervens J, Marks C, Hechler M, Plath T, Hansen D, et al. (2010) Effect of induced hypotensive anaesthesia vs isovolaemic haemodilution on blood loss and transfusion requirements in orthognathic surgery: a prospective, single-blinded, randomized, controlled clinical study. Int J Oral Maxillofac Surg 39(12): 1168-1174.

5. MacCarthy EP, Bloomfield SS (1983) Labetalol: a review of its pharmacology, pharmacokinetics, clinical uses and adverse effects. Pharmacotherapy 3(4): 193-219.

6. Jouppilla P, Kirkinen P, Keivula, Ylikorkala (1986) Labetalol does not alter the placental and fetal blood flow or maternal prostanoids in preeclampsia. Br J Obstet Gynaecol 93: 543-547.

7. Conner CS (1983) Labetalol: an alpha- and beta-blocker. Drug Intell Clin Pharm 17(7-8): 543-544.

8. Bosco FA, Braz J (2001) Beta-blockers in anesthesiology: clinical and pharmacological aspects. Rev Bras Anestesiol 51(5).

9. Chauvin M, Deriaz H, Viars P (1987) Continuous i.v. infusion of labetalol for postoperative hypertension. Haemodynamic effects and plasma kinetics. Br J Anaesth 59(10): 1250-1256.

10. Goldberg ME, McNulty SE, Azad SS, Cantillo J, Torjman M, et al. (1990) A comparison of labetalol and nitroprusside for inducing hypotension during major surgery. Anesth Analg 70(5): 537-542.

11. Fahed S, Grum DF, Papadimos TJ (2008) Labetalol infusion for refractory hypertension causing severe hypotension and bradycardia: an issue of patient safety. Patient Saf Surg 2: 13.

12. Kraemer HC, Theimann S (1987) How many subjects? Statistical power analysis in research. Behavior Research Methods, Instruments \& Computers 22(5): 486.

13. Ryu JH, Apfel CC, Whelan R, Jeon YT, Hwang JW, et al. (2012) Comparative prophylactic and therapeutic effects of intravenous labetalol $0.4 \mathrm{mg} / \mathrm{kg}$ and nicardipine $20 \mu \mathrm{g} / \mathrm{kg}$ on hypertensive responses to endotracheal intubation in patients undergoing elective surgeries with general anesthesia: a prospective, randomized, double-blind study. Clin Ther 34(3): 593-604.

14. Meftahuzzaman SM, Islam MM, Ireen ST, Islam MR, Kabir H, et al. (2014) Comparison of efficacy of labetalol and fentanyl for attenuating reflex responses to laryngoscopy and intubation. Mymensingh Med J 23(2): 242-248.

15.El-Shmaa NS, El-Baradey GF (2016) The efficacy of labetalol vs dexmedetomidine for attenuation of hemodynamic stress response to laryngoscopy and endotracheal intubation. J Clin Anesth 31: 267-73.

16. Sharma KJ, Greene N, Kilpatrick SJ (2017) Oral labetalol compared to oral nifedipine for postpartum hypertension: A randomized controlled trial. Hypertens Pregnancy 36(1): 44-47.

17. Apipan B, Rummasak D (2010) Efficacy and safety of oral propranolol premedication to reduce reflex tachycardia during hypotensive anesthesia with sodium nitroprusside in orthognathic surgery: a double-blind randomized clinical trial. J Oral Maxillofac Surg 68(1): 120-124.

18. Amr YM, Amin SM (2011) Effects of preoperative oral beta blocker versus intraoperative nitroprusside or esmolol on quality of surgical field during tympanoplasty. J Clin Anesth 23(7): 544-548. 
19. Amr YM, Amin SM (2012) Effects of preoperative $\beta$-blocker on blood loss and blood transfusion during spinal surgeries with sodium nitroprusside-controlled hypotension. Saudi J Anaesth 6(3): 263-267.

20. Kim NY, Yoo YC, Chun DH, Lee HM, Jung YS, et al. (2015) The Effects of Oral Atenolol or Enalapril Premedication on Blood Loss and Hypotensive Anesthesia in Orthognathic Surgery. Yonsei Med J 56(4): 1114-1121.

21. Prasant MC, Kar S, Rastogi S, Hada P, Ali FM, et al. (2014) Comparative Study of Blood Loss, Quality of Surgical Field and Duration of Surgery in Maxillofacial Cases with and without Hypotensive Anesthesia. J Int Oral Health 6(6): 18-21.

22. Nazir O, Wani MA, Ali N, Sharma T, Khatuja A, et al. (2016) Use of Dexmedetomidine and Esmolol for Hypotension in Lumbar Spine Surgery. Trauma Mon 21(3): e22078.

23. Lin S, McKenna SJ, Yao CF, Chen YR, Chen C (2017) Effects of Hypotensive Anesthesia on Reducing Intraoperative Blood Loss, Duration of Operation, and Quality of Surgical Field During Orthognathic Surgery: A Systematic Review and Meta-Analysis of Randomized Controlled Trials. J Oral Maxillofac Surg 75(1): 73-86.

24. Hadavi MR, Zarei Y, Tarogh S (2015) Comparison of effects of labetalol and nitroglycerine on intraoperative blood loss and surgical field quality in rhinoplasty surgery. World J Plast Surg 4(1): 60-65.
25. Jeong J, Portnof JE, Kalayeh M, Hardigan P (2016) Hypotensive anesthesia: Comparing the effects of different drug combinations on mean arterial pressure, estimated blood loss, and surgery time in orthognathic surgery. J Craniomaxillofac Surg 44(7): 854-858.

26. Chung PC, Ng YT, Hsieh JR, Yang MW, Li AH (2006) Labetalol pretreatment reduces blood pressure instability during surgical resection of pheochromocytoma. J Formos Med Assoc 105(3): 189193.

27. Mashour GA, Sharifpour M, Freundlich RE, Tremper KK, Shanks A, et al. (2013) Perioperative metoprolol and risk of stroke after noncardiac surgery. Anesthesiology 119(6): 1340-1346.

28. Sanath KSB, Date R, Woodhouse N, El-Shafie O, Nollain K, et al. (2014) Successful Management of Phaeochromocytoma using Preoperative Oral Labetalol and Intraoperative Magnesium Sulphate: Report of four cases. Sultan Qaboos Univ Med J. 2014; 14(2): e236-240.

29. Sirivanasandha B, Sakaew A, Sutthivaiyakit K, Raksamani K, Waitayawinyu P, et al. (2015) An Equivalence Trial Comparing Labetalol and Diltiazem in Controlling Emergence Hypertension after Supratentorial Tumor Surgery. J Med Assoc Thai 98(11): 1104-1111.

\section{Your next submission with Juniper Publishers will reach you the below assets}

- Quality Editorial service

- Swift Peer Review

- Reprints availability

- E-prints Service

- Manuscript Podcast for convenient understanding

- Global attainment for your research

- Manuscript accessibility in different formats ( Pdf, E-pub, Full Text, Audio)

- Unceasing customer service

Track the below URL for one-step submission https://juniperpublishers.com/online-submission.php 